\title{
Pulsações de sentido em "O pulsar": uma possível leitura
}

\author{
Marcelo TÁPIA (USP)
}

RESUMO: Este artigo pretende realizar uma leitura analítica do poema "O pulsar", de Augusto de Campos, a partir de conceitos da semiótica de C. S. Peirce e da semiótica desenvolvida a partir das proposições de A. J. Greimas. Tal leitura considera as relações paradigmáticas entre significantes "verbais" e aquelas estabelecidas pelos elementos sígnicos "visuais" presentes no poema, envolvidas na construção de uma relação semisimbólica.

PALAVRAS-CHAVE: análise semiótica, poesia visual, Augusto de Campos.

\begin{abstract}
This article intends to realize an analytical reading of the poem " $O$ pulsar", by Augusto de Campos, considering concepts of the semiotic created by C.S. Peirce and the semiotic developed from A.J. Greimas' propositions. This reading contemplates the paradigmatic relations between the "verbal" significants and those established by the "visual" signical elements present in the poem, and that integrate the construction of a semi-symbolic relation.
\end{abstract}

KEYWORDS: Semiotical analysis; visual poetry; Augusto de Campos. 
O objeto de análise deste artigo será o poema "O pulsar", de Augusto de Campos. Integrante da série "Stelegramas" (1975-1978), incluída no volume Viva vaia - Poesia 1949-1979, o poema foi produzido utilizando-se de um recurso ao qual o poeta costumava lançar mão à época: a "Letraset", sistema de letras transferíveis que dispunha, principalmente em sua linha "Letragraph", de tipos "fantasia", ou seja, letras com desenhos originais que visavam a diferenciação e o ineditismo, com o objetivo de serem utilizadas em trabalhos especiais com acentuado teor gráfico ou plástico. Diversas criações de A. de Campos incorporavam o design de tipos da referida linha, como "Eco de Ausonius", "The tyger / O tygre", "Inseto", "O", "Miragem" e "O quasar" (estes quatro últimos integrantes de "Stelegramas"), entre outros. Assim é o poema "O pulsar":

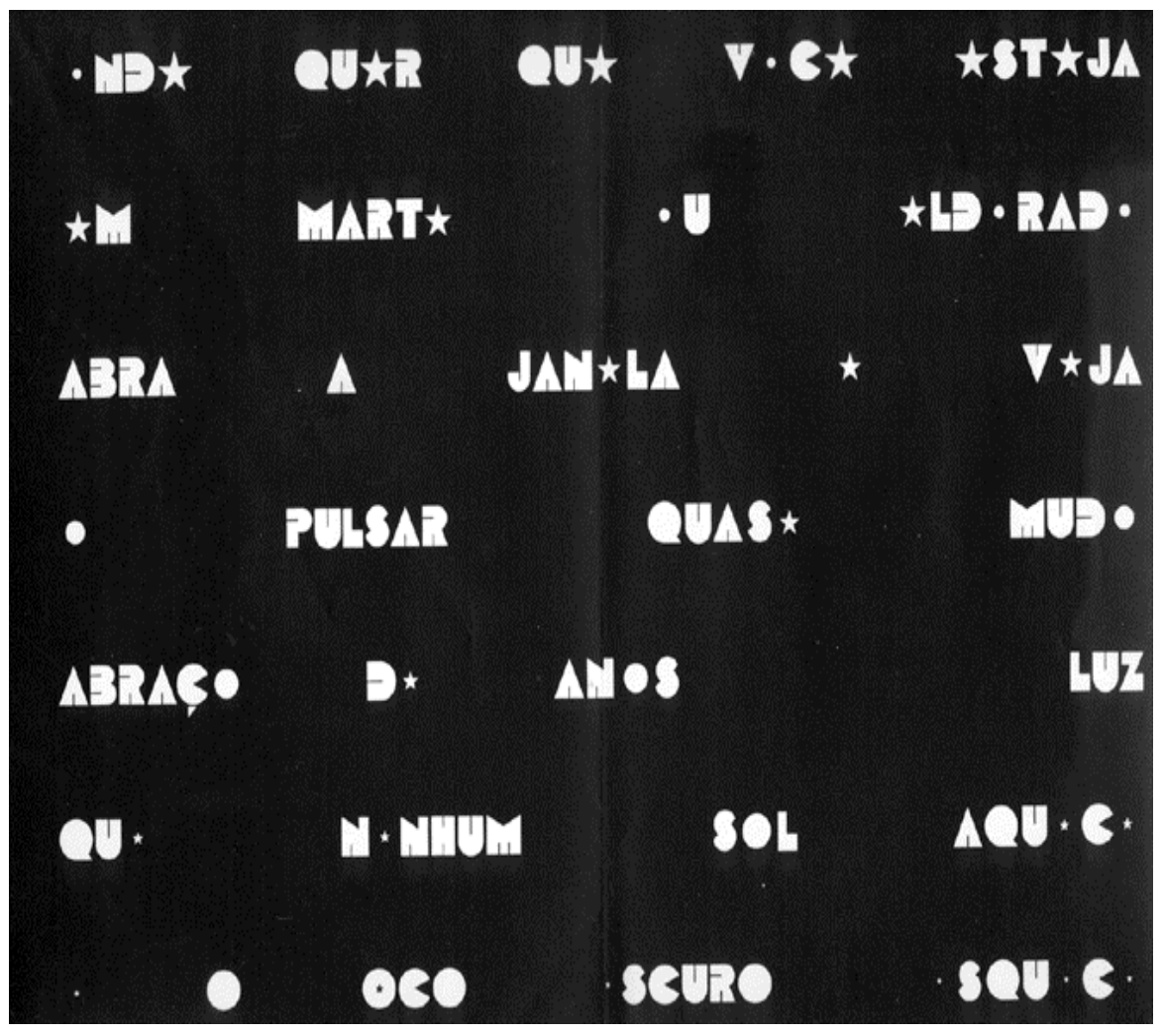

A tipologia utilizada em tal poema caracteriza-se pelo corpo "cheio" das letras, nos quais inserem-se traços finos que complementam seu aspecto identificador. A letra 
"o" (que nesse tipo de letra configura-se como uma circunferência preenchida) assume uma dimensão icônica (para utilizarmos a classificação adotada na semiótica criada por Charles Sanders Peirce); a letra "e" é substituída pela representação visual de uma estrela, que podemos considerar um ícone ${ }^{1}$. A utilização dos elementos icônicos trará novas relações de sentido ao poema, além de seu nível verbal, que interagem com este. Mas inicialmente, antes que se entre no âmbito visual do poema, atentemos para a sua dimensão exclusivamente verbal.

"O pulsar" compõe-se de sete versos de métrica variável, embora possam ser lidos de forma a prevalecerem redondilhas maiores: o primeiro, "onde quer que você esteja", conta com oito sílabas, ou sete (elidindo-se a vogal final de "você", e a primeira de "esteja", elisão esta um tanto forçada devido à tônica que incide sobre o primeiro "e"); o segundo, "em marte ou eldorado", com seis (embora se possa lê-lo com sete, não realizando a elisão entre a vogal final de "marte" e a primeira de "ou"); o terceiro, "abra a janela e veja", com sete (se não se elidem a vogal átona final "a", de "abra", e o "a" seguinte) ou seis (caso se faça tal elisão); o quarto, "o pulsar quase mudo", com seis; o quinto, "abraço de anos luz", com sete (se não se elidem a vogal "e", de "de", e a vogal "a", de "anos") ou seis (caso se faça essa elisão); o sexto, "que nenhum sol aquece", com seis; o sétimo, "e o o(e)co escuro esquece" (como se verá adiante, o "e" sobrepõese ao "o" fazendo com que duas palavras distintas coexistam), com sete (se não se elidem a vogal átona "e", do início do verso, e o "o" seguinte), ou seis (caso se faça a elisão). (Apesar da pequena irregularidade métrica, o poema apresenta uma perceptível coerência rítmica.) As rimas se organizam conforme o esquema abaccdd, sendo que entre "mudo" e "luz" ( $c c)$ ocorre uma rima toante; há, também, assinale-se, uma correspondência entre a sílaba final de "eldorado" e a de "mudo", que no entanto não se caracteriza como rima, pois a coincidência exclui a vogal tônica final do verso, que a antecede.

Quanto aos versos, o poema apresenta uma estrutura tradicional, que poderia pertencer a um poema dentro dos parâmetros convencionais, no sentido de ser exclusivamente verbal; embora inclua vocábulos ("pulsar", "anos luz") que provêm de um âmbito científico de conhecimento, sua utilização não chega a destoar do emprego usual na língua ("pulsar", além de ser o substantivo cujo significado é "radiostrela que emite ondas de rádio com a duração de 35 milionésimos de segundo" (Dicionário Houaiss), portanto de uso técnico, também pode ser o infinitivo do verbo que apresenta diversos significados (colhidos no mesmo dicionário), todos possivelmente ligados ao poema: "ter pulsação, latejar"; ferir, tocar, tanger; tocar (instrumento, música); pôr em movimento ritmado; ter palpitação, palpitar, arquejar; etc. (o próprio nome do objeto estelar, diga-se, foi-lhe atribuído por sua natureza "pulsante", uma vez que suas emissões eletromagnéticas "se reproduzem a intervalos extremamente regulares" (Larousse, p. 4.832); "anos luz", embora seja expressão ligada ao repertório técnico da física contemporânea - "ano-luz" é a "unidade que corresponde à distância percorrida

\footnotetext{
${ }^{1}$ Inclui-se, mais à frente, um comentário acerca da classificação deste signo.
} 
pela luz no vácuo, durante um ano" "2 -, é bastante utilizada na fala informal, possibilitando que o texto mantenha um certo teor de coloquialidade que o aproxima, inclusive, de uma letra de música popular. O próprio Augusto de Campos sugeriu, certa vez, que o primeiro verso de seu poema poderia integrar uma canção de Lupicínio Rodrigues; isso seria, diga-se, perfeitamente cabível considerando-se, inclusive, sua compatibilidade com o que poderia ser uma canção cujo tema se ligasse à idéia de encontro e desencontro entre um homem e uma mulher, à distância entre amantes, à desilusão amorosa etc.

Sob o ponto de vista do plano de conteúdo (para usar-se sistema de classificação de Hjelmslev), temos um "eu" (o enunciador) que se dirige a um "você" que se encontra distante; este eu, conforme um nível mais imediato de entendimento acerca do que diz o poema, faz uma proposição genérica a alguém, em qualquer parte do universo, para que receba um "pulsar" distante. Podemos considerar também segundo outra possibilidade de interpretação - que o "eu lírico" esteja se dirigindo àquele que é o próprio receptor do poema, ou seja, a um possível leitor longínquo; tal distância, por sua vez, pode ser entendida de diferentes maneiras, conforme a atribuição de sentido que se lhe faça.

Mas o poema ainda pode sugerir - trata-se esta, apenas, de uma possibilidade interpretativa, entre outras mais, que orientará as reflexões acerca do poema a serem desenvolvidas neste estudo - que seja, o sujeito a quem o "eu" se dirige, envolvido com o primeiro por um laço afetivo ou amoroso; há a mensagem que propõe, "ordena", com o uso do imperativo, uma ação ao sujeito "você", ou melhor, que exorta este sujeito à ação - por meio do que Jakobson denominaria "função conativa" da linguagem - de abrir a janela e ver algo ("o pulsar") que se revela e se realiza com a sugestão de um contato físico ("abraço") - embora vinculado à noção de imensa distância ("de anos luz”) -, espécie de presentificação que se perde, em seguida, no olvido (ligado, este, ao próprio distanciamento). Não há participação da resposta do segundo sujeito, mas apenas um aparente resultado da própria ação desempenhada pelo enunciador. Tais observações nos servirão de base para uma breve análise posterior, no campo da semiótica.

Relativamente ao plano de expressão (tratando-se, ainda, dos versos em seu nível verbal, sem a consideração do uso dos elementos visuais incorporados ao poema), podem-se observar efeitos de sonoridade - como relações aliterantes e assonantes, além das rimas já especificadas - que projetam o eixo de seleção sobre o de combinação, o paradigma sobre o sintagma, projeção esta própria da "função poética da linguagem", formulada por Jakobson, que, embora não restrita à poesia, prepondera nela - o poema em questão associaria, portanto, as funções poética (que lhe é própria pela própria "natureza" do objeto de arte verbal) e conativa. (Associaria também, mencione-se, a

2 Note-se que, no verso de A. de Campos, aparece "anos luz" e não "anos-luz”, forma esperada de grafia da expressão. Ao se eliminar o hífen do composto, parece manter-se a independência dos termos, capaz de gerar sentidos autônomos; a distância graficamente estabelecida entre tais termos, além de referir-se metalingüisticamente ao próprio sentido de "distância" que a expressão envolve, enfatiza sua autonomia, permitindo a leitura da palavra "luz", isolada. 
função metalingüística à função poética, no caso da primeira possibilidade interpretativa aqui anunciada, ou seja, a de que o "eu lírico" se dirigisse ao leitor do poema). Quanto às relações de sonoridade presentes nos versos, destaquem-se, por exemplo, as que se estabelecem entre "quer", "que", "quase", "que", "аquece", "осо" ; "еscuro"; "esquece"; esteja; janela; veja; "você"; "pulsar"; "abraço"; "sol"; "aquece"; "esquece"; etc.

Quanto ao aspecto geral do poema, observe-se que integra seu plano de expressão a disposição gráfica das palavras e dos versos: organizado em um bloco pois seus versos se alinham à esquerda e à direita - "O pulsar" apresenta uma unidade espacial delimitada, compondo-se como um universo demarcado em que se processam relações internas entre seus elementos; tais relações envolvem os espaços que separam as palavras, que podem funcionar como silêncios, ora mais breves, ora mais longos: note-se o alongamento do silêncio entre "anos" e "luz", que, como já foi referido, traz uma dimensão metalingüística de sentido.

Voltando ao plano do conteúdo, e, portanto, à "rede de relações" (Pietroforte, 2005 , p. 13) que compõem o sentido, façamos, como primeiro nível dentre os diversos em que procederemos a tentativas de análise de "O pulsar", uma reflexão dentro do âmbito da semiótica desenvolvida a partir das proposições de A. J. Greimas. Embora não haja propriamente uma "narrativa" no poema em questão, busquemos, no grau maior de abstração, correspondente ao denominado "nível fundamental" (ou "nível profundo") - o mais amplo em relação a um tema comum entre narrativas -, identificar uma "categoria semântica mínima", formada por termos simples que a definem por meio da relação entre eles, relativa à temática ligada a uma possível "narrativa", parcial ou apenas sugerida, do poema. Poderíamos, talvez, identificar como dois termos contrários "união" e "separação", ligados a outros possíveis opostos, "encontro" e "desencontro", envolvendo a idéia de proximidade e distância. Se tomarmos os termos "união" e "separação", poderemos construir o seguinte "quadrado semiótico":

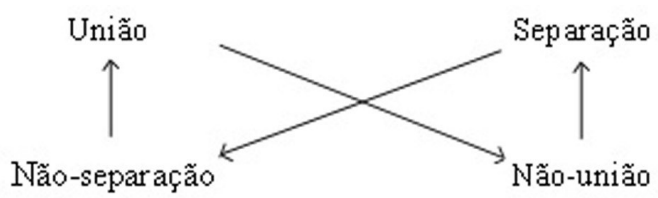

O quadrado semiótico "prevê uma sintaxe sumária" que deve apreender "em seus termos os estados narrativos [...] [e] suas transformações" (Tatit, 2002, p. 198). A relação entre tais termos seria, assim, responsável pela orientação do sentido mais geral e abstrato do poema. O sujeito enunciador afirma, inicialmente, a separação (a distância, o desencontro); ao exortar o outro sujeito a desempenhar uma ação, ele nega esse termo, buscando a união (o encontro), que se realiza na palavra "abraço" (presente apesar da indicação de distância, que permanece na expressão "anos luz"). Os opostos convivem no poema em toda a sua extensão: a união se realiza, mas é concomitantemente negada 
(não-união) pela distância que não deixa de existir; a separação se afirma pela manutenção da idéia de distância, mas é negada (não-separação) pela possibilidade do encontro ("abraço").

Compreendendo-se uma "narrativa mínima"” como uma transformação entre dois estados, pode-se dizer que o sujeito enunciador, no poema, encontra-se, inicialmente, em disjunção com o (possível) objeto - o outro sujeito - a que se dirige, que pode ser de seu desejo ou do propósito de (re-)união (ou encontro) ${ }^{4}$; por meio de um fazer, o primeiro sujeito entra em conjunção com o outro, seu objeto, tornada viável pelo contato que pode se estabelecer a partir da proposta de que este "abra a janela" e "veja" o "pulsar quase mudo" que passa a consistir em um "abraço", indicativo do encontro. A ação, portanto, é responsável pela transformação de um estado em outro. $\mathrm{O}$ último verso do poema sugere uma nova disjunção, representada pelo esquecimento (um outro "fazer" manifestado, que transforma): "e o o(e)co escuro esquece", esquecimento este, como já se disse, associado à idéia de distância, já reforçada pelo verso anterior "que nenhum sol aquece" (que se pode entender como a sugestão de algo tão distante a que nenhum calor pode chegar). Dessa forma, poderíamos ter uma sequiência, em termos de disjunção e conjunção, assim representada:

$$
\text { (Suj. U Obj.) } \rightarrow \text { (Suj. } \cap \text { Obj.) } \rightarrow(\text { Suj. U Obj.) }
$$

A fim de prosseguirmos nossa análise visando-se a totalidade do poema, representada pelos planos de conteúdo e de expressão, consideremos sua estruturação no nível do "significante" (para usar-se, aqui, a terminologia de Saussure). Além de nos referirmos aos elementos de ordem expressiva que caracterizam a presença da função poética da linguagem no poema em questão (função esta que, em termos da semiótica de Peirce, "se marca pela projeção do ícone sobre o símbolo", esclarecendo-se que, enquanto os ícones são "signos por similaridade", os símbolos são "signos por contigüidade" (Pignatari, 1977, pp. 10-14)), ou seja, que mantêm, em relação a seu objeto, uma conexão por convenção ou "pacto coletivo" (Santaella, 1983, p. 92), devemos focalizar o papel desempenhado pelo uso dos ícones sobrepostos à própria dimensão verbal do poema (que já apresenta os elementos icônicos, como os efeitos sonoros mencionados, caracterizadores do poema e da própria poesia), associados, portanto, ao texto propriamente dito. Nesse aspecto, como já se mencionou, a letra "o" (o poema utiliza, mencione-se, letras maiúsculas) da tipologia usada é uma

\footnotetext{
${ }^{3}$ Com a ressalva já mencionada de que no poema não há propriamente uma narrativa, mas apenas uma ação que a sugere; contudo, creio na possibilidade, por analogia, do emprego deste tipo de análise, ainda que vinculada a uma dimensão parcialmente narrativa do texto.

${ }^{4}$ Reafirme-se que se trata, esta, de uma possibilidade interpretativa (entre outras), que norteia esta análise.
} 
circunferência preenchida, um círculo, o que possibilita sua utilização direta como "figura" (a rigor, um "hipo-ícone" - por representar um objeto por semelhança, já que o ícone propriamente dito consiste num "quali-signo": uma "pura qualidade", um "primeiro" (1983, pp. 85-86)); no caso na letra "e", esta é, conforme já se disse, substituída pela representação de uma estrela, que assume, portanto, seu valor fonético (que pode ser tanto do fonema /e/ como do fonema /i/; no caso do "o", pode ser tanto de /o/ como de $/ \mathrm{u} /)$.

Embora tenhamos considerado tais signos como ícones (ou hipo-ícones), pela relação analógica que estabelecem com seus possíveis objetos (distinguindo-os, assim, da palavra, exemplo modelar de símbolo, na terminologia de Peirce), estes também apresentam uma dimensão simbólica: a usual representação geométrica de uma estrela, embora uma "figura", envolve a convencionalidade, que faz com que reconheçamos tal representação, abstrata e genericamente, como a de uma estrela (o Aurélio refere-se, em seu verbete "estrela", à "figura convencional que tem cinco ou seis pontas"); no caso do círculo, este pode ser uma representação do sol, que, embora mantenha, igualmente, uma relação de semelhança com tal objeto, não exclui a convenção. Podemos admitir, assim, que tais signos apresentem uma espécie de "natureza híbrida"; contudo, para efeito desta análise, que envolve a distinção (ou contraposição) entre os elementos verbais e os visuais, optamos por designá-los por seu teor de ícone. Diga-se no entanto, ainda, que tais signos podem adquirir outros níveis simbólicos, se se considerar que o círculo e a estrela podem guardar outras relações convencionadas com possíveis e reconhecidos significados; o primeiro, se entendido como "sol", poderá significar "luz" e, mesmo, "alegria, felicidade" (o Aurélio registra estes sentidos "figurados" da palavra); o segundo poderá adquirir os significados de "destino, sorte, fado" e, até (entre outros), o de "pessoa muito querida" (também encontráveis no Aurélio). A atribuição do significado de "sol" à figura circular se reforça pelo aspecto semântico do poema (que contém tal palavra) e pela relação de oposição à figura da estrela; mas essa atribuição, frise-se, liga-se a uma escolha interpretativa. Entre outras possíveis interpretações ${ }^{5}$, há que se mencionar aquela que veria no círculo a representação do próprio "pulsar": sendo, os pulsares, "estrelas de nêutrons com massa próxima à do sol, mas com cerca de 10 km de diâmetro" (Larousse, 1998, p. 4.832) - portanto estrelas muito pequenas e muito densas -, "em rotação muito rápida, funcionando como fonte de emissão de ondas eletromagnéticas, tal como um farol" (Id., ib.), não seria inadequado que se fizesse tal representação. Considere-se, no entanto, que tanto o "sol" (se assim virmos o círculo) que também é uma estrela - como a "estrela" são potencialmente pulsares, uma vez que estes resultam de "supernovas", estrelas maciças cujas regiões centrais entram em colapso gravitacional, produzindo "a formação de uma estrela de nêutrons ou de um buraco negro" $(1998, \text { p. } 5.539)^{6}$.

${ }^{5}$ Uma dessas possibilidades certamente seria a de atribuir-se ao círculo o significado de "lua"; tal opção evidentemente dirigiria a análise por caminho diverso do percorrido neste estudo.

${ }^{6}$ Tal formação é "seguida de um choque que expulsa o envoltório da estrela a uma velocidade de dezenas de milhares de quilômetros por segundo. [...] A maior parte da massa da estrela é ejetada durante a explosão [...]. A fração de massa não ejetada forma 
Os ícones são utilizados de modo a suas dimensões se alterarem ao longo do poema: o círculo aparece pequeno no primeiro verso, aumentando de tamanho a cada linha em que aparece; a estrela surge inicialmente grande, para diminuir gradativamente de tamanho a cada verso, ambos numa sucessão regular de transformação entre um verso e outro. A estrela aparece em todos os versos; o círculo (o "o", portanto) não está presente em apenas um dos versos, o terceiro (exatamente aquele em que ressalta a função conativa da linguagem; mas este é um ponto a ser retomado em nota, mais à frente).

Podem-se constatar, em relação a tais signos, diversos níveis de oposição que trarão subsídios à continuidade de nossa análise: em termos de "forma", um é redondo, o outro angular; um cresce, o outro descresce; em termos de "conteúdo", um representa o sol, outro uma estrela; um é, portanto, masculino, e o outro, feminino. É fácil, também, confirmar-se, numa breve enquete em que se submetam ambos os signos a uma certa quantidade de sujeitos, o dado que se tem intuitivamente acerca da "altura" (no sentido musical de vibração) correspondente ao som que seja vinculado a cada um deles: a estrela será identificada com o som agudo (elevado na escala musical; freqüência rápida), enquanto o círculo, com o som grave (baixo na escala musical; freqüência lenta).

Este último aspecto traz ao poema uma dimensão de partitura musical, que, diferentemente da "melodia de timbres" (klangfarbenmelodie) - o timbre podendo definir-se como a "cor do som", como na fórmula alemã - orientadora de série anteriormente produzida pelo autor, "Poetamenos" (1953), parece não envolver diferentes vozes (com timbres diversos), mas um contínuo solo que se estabelece entre um extremo, grave, e outro, agudo, passando por uma altura intermediária: três níveis sonoros, portanto, que constroem a melodia. Tal procedimento de leitura musical foi levado a termo por Caetano Veloso, em gravação que acompanhou a edição original do livro Viva vaia (1979).

A oposição de forma, e a vinculação de uma das formas com o astro associado ao dia (o sol) e da outra com um astro associado à noite (a estrela) liga-se a uma oposição de períodos dentro uma unidade cíclica (opostos complementares); tal oposição inclui o "gênero" (masculino e feminino) entre os signos, que sugere a identificação de dois sujeitos de sexos diferentes. Se podemos vincular cada um dos ícones a cada um dos sujeitos ${ }^{7}$, cuja diversidade se liga à diferenciação da forma, a idéia de separação e desencontro se acentua com o aspecto da evolução inversa que cada um apresenta: enquanto um aumenta de tamanho, o outro diminui, indicando-se, portanto,

um resíduo muito compacto sob a forma de uma estrela de nêutrons em rotação, observada como um pulsar". (Larousse, 1998, p. 5.539.)

${ }^{7}$ A partir da identificação dos ícones com cada um dos sujeitos, pode-se dizer que, talvez (retomando-se um aspecto já apontado), a ausência do círculo no verso (o terceiro) em que predomina a função conativa localize nele a exclusiva presença do receptor da mensagem, que poderá ter contato com o emissor por meio da execução de sua ordem. 
sentidos opostos (entenda-se "sentido", aqui, no emprego que a física faz do termo). Em termos da semiótica peirceana, pode-se dizer, num exercício de dedução por analogia, que a variação do tamanho dos ícones assume uma função indicial, se passamos a ver a imagem atrelada à diminuição ou aumento de sua dimensão como pegadas, rastros, deixados pelo "objeto" estrela e pelo "objeto" sol: índices de sua "passagem" pelas linhas ("lugares") do poema (o índice, para Peirce, "é um signo que como tal funciona porque indica uma outra coisa com a qual está factualmente ligado" (Santaella, 1983, p. 90)).

Sendo a palavra, o verso e o poema lineares (cite-se o princípio da "linearidade do significante", de Saussure), é na mesma linha, mas em sentidos inversos, que os dois ícones "caminham", afastando-se. A presença absoluta da estrela, no início, sugere a localização no "lugar", ou plano, em que esta se encontra; a presença total do sol, no final, sugere o deslocamento do lugar, ou plano, para seu correspondente inverso; podese, talvez, pensar no lugar da emissão da mensagem e no lugar de sua recepção, como os dois extremos entre os quais "circula" a mensagem.

Se o desencontro, a separação, se apresenta como tendência, como força que promove o movimento, esta não impede que se consubstancie o encontro, a união: há um momento, no último verso do poema, em que - como já se referiu anteriormente - a estrela se sobrepõe ao sol (ou seja, o "e" sobrepõe-se ao "o", o agudo ao grave, o feminino ao masculino), e, portanto, um sujeito a outro. Os opostos, nesse momento, coexistem, fundindo-se num todo; o ícone menor, a estrela, deixa de ser apenas uma estrela, e passa a ser um elemento do círculo, um "vazio" integrante dele, numa espécie de referência metalingüística ao sentido da palavra em que ele se insere: "oco" (o "o" de "oco" fica, assim, oco); pela inserção da estrela (ou seja, do "e") surge, concomitantemente a "oco", a palavra "eco", que também assume uma função metalingüística (neste, como no caso anterior, associada, evidentemente, à função poética), traduzindo o próprio significado na produção do eco da outra palavra com a qual coexiste. É importante notar que, com a sobreposição e a conseqüente simultaneidade - que sugere a emissão simultânea dos sons numa leitura, com duas vozes sobrepostas (tal como fizera Caetano Veloso em sua gravação, na qual utilizou recursos e estúdio para fundir os dois registros diversos de sua voz) - subverte-se o princípio saussureano da linearidade do significante.

Os signos (ícones) em questão permitem, também, uma breve discussão quanto ao aspecto de sua arbitrariedade, embora tal discussão exceda o domínio fônico, objeto da linguiística: se o "o" passa a ser a figura de um círculo, que pode representar o sol, esta relação (nos planos de expressão e de conteúdo) não é simplesmente arbitrária (e, por isso mesmo, no sistema de Peirce, permite sua qualificação como ícone - signo por similaridade); a própria palavra "sol", que contém o ícone "formado" pelo "o", passaria a ser, assim, neste contexto, para usar a terminologia de Saussure, "relativamente motivada", embora primeiramente não no plano fônico, mas no de sua grafia - no entanto, o plano do som também se inclui nesta aparente motivação: como diria Fiorin, referindo-se a proposições de Jakobson quanto à existência de motivações "em todos os níveis da língua", "Os sons parecem ter um simbolismo universal. A oposição de fonemas graves, como o /a/, e agudos, como o /i/, é capaz de sugerir a imagem do claro 
e do escuro, do pontudo e do arredondado, do fino e do grosso, do ligeiro e do maciço". $\mathrm{O}$ "o" (e, conseqüentemente, os fonemas /o/ e /u/ por ele representados) pode, assim, indicar um som cujo simbolismo passe a atribuir uma relativa motivação à palavra ("sol") a ele identificada.

Tratando-se de arbitrariedade e motivação do signo, passemos a abordar, a seguir, o poema à luz do conceito de semi-simbolismo. Mas, antes, façamos um parêntese a fim de estender um pouco a compreensão acerca do que se entende por "motivação". Esta caracterizaria a poesia ("motivação poética"), e corresponderia à "existência de relações não-arbitrárias entre o significante e o significado" (Greimas, 1976, p. 29). Desde as postulações de Jakobson, a questão da não-arbitrariedade absoluta do signo ganha uma dimensão fundamental para a análise do texto poético; a esse respeito, diz Haroldo de Campos: "Como observa Mattoso Câmara, Jakobson nega a arbitrariedade absoluta do signo fonológico, sustentando que toda língua, necessariamente, procede a uma seleção entre um limitado número de tipos de sons vocais e suas combinações [...] Em todo caso, [...] na poesia (onde, como proclama Jakobson, reina o jogo de palavras, a paronomásia, figura esta entendida num sentido amplo de correlação entre som e sentido), esta arbitrariedade não existe. [...]" (1975, p. 143). Nas palavras de Greimas, "os objetos poéticos podem ser ditos motivados, desde que se entenda por motivação, dentro da tradição saussureana, a existência de relações não-arbitrárias entre o significante e o significado. [...] a motivação poética [...] [é] susceptível de ser definida como a realização das estruturas paralelas e comparáveis que estabelecem correlações significativas entre os dois planos da linguagem [(o da expressão e o do conteúdo)] fornecendo, com isto, um estatuto específico aos signosdiscursos assim manifestados." Para ele, "só é possível falar justificadamente em motivação relativa de objetos poéticos" (1976, p. 29). Como diria Fiorin, "é na poesia [...] que a motivação do signo aparece em toda sua força. O poeta busca motivar a relação entre o significante e o significado" (2002, p. 63).

Conforme observa Pietroforte, "essa relação entre expressão e conteúdo é chamada semi-simbólica. Ela é arbitrária porque é fixada em determinado contexto, mas é motivada pela relação estabelecida entre os dois planos da linguagem. Assim, partindo dos conceitos de signo [("uma entidade psíquica" que une "um conceito e uma imagem acústica”) (Saussure, 1977, p. 82)] e de símbolo [(“O símbolo tem como característica não ser jamais completamente arbitrário [...] o símbolo da justiça, a balança, não poderia ser substituído por um objeto qualquer [...]" (1987, p. 82)] de F. de Saussure, define-se o semi-simbolismo entre o arbitrário do signo e o motivado do símbolo". O autor esclarece que "a projeção do eixo paradigmático no sintagmático" (tanto no plano de expressão como no de conteúdo), que define a função poética da linguagem, embora responsável "pelos efeitos de poeticidade", não é necessariamente semi-simbólica: "[...] a relação entre uma forma de expressão e uma forma de conteúdo manifesta-se quando há uma relação entre os eixos paradigmáticos de cada uma delas, e quando eles são projetados no eixo sintagmático. Se em uma pintura, por exemplo, as cores quentes são relacionadas a conteúdos do sagrado, e as cores frias, do profano, em seu texto há uma projeção no eixo sintagmático da relação entre os paradigmas que formam a categoria de expressão cor quente vs. cor fria e a categoria de conteúdo sagrado vs. profano. 
Assim, toda relação semi-simbólica é poética, mas nem toda relação poética é semisimbólica" (2004, pp. 8-10). (As citações são longas mas pertinentes, servindo de referência à breve análise desenvolvida a seguir.)

No poema "O pulsar", como vimos, tem-se, além da projeção das relações paradigmáticas estabelecidas entre significantes "verbais" (como rimas), a projeção das relações paradigmáticas estabelecidas pelos elementos sígnicos "visuais" presentes no poema. Estes elementos (o círculo, no plano da expressão, "sol" no plano do conteúdo; a representação geométrica de uma estrela, no plano da expressão, "estrela", no plano do conteúdo) estabelecem uma relação semi-simbólica: ocorre a relação entre a forma de expressão e a forma de conteúdo de ambos, pois os eixos paradigmáticos de cada uma delas relacionam-se, e se projetam no eixo sintagmático. O círculo, cuja forma arredondada se opõe à estrela, de forma angulosa, está relacionado ao "sol" (com os significados e relações simbólicas que possa determinar), ao masculino, ao dia, e a um dos sujeitos envolvidos no poema; a estrela relaciona-se a uma "estrela" (com os significados e relações simbólicas que possa determinar), ao feminino, à noite, e a um dos sujeitos. Tais signos, assim, relacionam-se a conteúdos específicos, havendo projeção no eixo sintagmático da relação entre os paradigmas que formam a categoria de expressão círculo x estrela e a categoria de conteúdo, por exemplo, "masculino $\mathrm{x}$ feminino". Na dimensão fônica, a forma de expressão do som grave opõe-se à forma de expressão do som agudo, dando-se da mesma maneira a relação entre tais formas de expressão e as formas de conteúdo de ambos, e a conseqüente projeção dos eixos paradigmáticos de cada uma delas no eixo sintagmático.

Voltemos, por fim, nossa análise do poema a um plano que tenha por fundamento o conceito de "código": coerentemente à própria noção de signo para Saussure (para quem "na língua não há senão diferenças, ou seja, [...] cada elemento lingüístico deve ser diferente dos outros elementos com os quais contrai relação. Por isso é preciso considerar o signo [...] em seus contornos, dados por suas relações com outros signos" (Fiorin, 2002, p. 58)), o código tem, como princípio de sua formação, "a diferença relativa entre seus constituintes" (Pietroforte, 2004, p. 146). Assim, "o elemento que faz parte de uma estrutura [de código] é definido de dois modos que se complexificam: em sua identidade, ou seja, nas propriedades que o tornam reconhecível; e em sua alteridade, ou seja, na relação que contrai com os demais elementos do sistema" (p. 146). Em "O pulsar", observe-se, é a relação de alteridade entre os signos (ícones) do círculo e da estrela (além das propriedades que definem a identidade de cada um) que possibilita a formação de um "código próprio" do poema, cujas relações de sentido se estabelecem nos diversos níveis que a leitura interpretativa nos permite, criando-se a condição para que se construa a possibilidade da "motivação poética". 


\section{REFERÊNCIAS BIBLIOGRÁFICAS}

CAMPOS, Augusto de. Viva vaia - poesia 1949-1979. São Paulo: Duas Cidades, 1979.

CAMPOS, Haroldo de. A arte no horizonte do provável. São Paulo: Perspectiva, 1975.

FERREIRA, Aurélio B. de Holanda. Novo Aurélio século XXI - O dicionário da língua portuguesa. Rio de

Janeiro: Nova Fronteira, 1999.

FIORIN, José Luiz (org.). Introdução à lingüística. São Paulo: Contexto, 2002.

Grande Enciclopédia Larousse Cultural. São Paulo: Nova Cultural, 1998.

GREIMAS, A. J. (org.). Ensaios de semiótica poética. São Paulo: Cultrix, 1976.

HOUAISS, Antônio e VILLAR, Mauro de Salles. Dicionário Houaiss da língua portuguesa. Rio de Janeiro:

Objetiva, 2001.

PIETROFORTE, Antonio Vicente. Semiótica visual: os percursos do olhar. São Paulo: Contexto, 2004.

PIGNATARI, Décio. Comunicação poética. São Paulo: Cortez \& Moraes, 1977.

SANTAELLA, Lucia. O que é semiótica. São Paulo: Brasiliense, 1983.

SAUSSURE, Ferdinand de. Curso de lingüística geral. São Paulo: Cultrix, 1977.

\section{Como citar este artigo:}

TÁPIA, Marcelo. Pulsações de sentido em "O pulsar": uma possível leitura. Estudos Semióticos, Número 3, São Paulo, 2007. Disponível em $<$ www.fflch.usp.br/dl/semiotica/es $>$. Acesso em "dia/mês/ano". 